FELIPE JAMES ARRUDA PINTO

Conflitos de vizinhança no Direito Civil contemporâneo

Dissertação de Mestrado

Orientador: Professor Doutor Marco Fábio Morsello

UNIVERSIDADE DE SÃO PAULO

FACULDADE DE DIREITO

São Paulo-SP

2018 

FELIPE JAMES ARRUDA PINTO

\section{Conflitos de vizinhança no Direito Civil contemporâneo}

Dissertação apresentada à Basnca Examinadora do Programa de Pós-Graduação em Direito, da Faculdade de Direito da Universidade de São Paulo, como exigência parcial para obtenção do título de Mestre em Direito, na área de concentração Direito Civil, sob a orientação do Prof. Dr. Marco Fábio Morsello.

UNIVERSIDADE DE SÃO PAULO

FACULDADE DE DIREITO

São Paulo-SP 

Banca Examinadora 



\section{AGRADECIMENTOS}

Primeiramente agradeço a Deus, por absolutamente tudo. A Ele minha própria vida, e principalmente a forma como ela aconteceu, por intermédio da Virgem Maria, de São Jorge e de Santa Rita de Cássia.

Eterna gratidão aos meus pais, Izilda e Jair; minha irmã, Laissa; e minha querida Vicky, por minhas bases como pessoa e minha sensação de pertencimento ao mundo que habito. Inexplicável o sentimento que sinto por todos.

A minha família, em toda sua extensão e abrangência, pelo incentivo e pela formação da minha identidade. Especial destaque aos meus tios; aos meus primos; e, sobretudo, meus avós: Sebastião, Narcisa, o saudoso Farid Salomão, que mesmo distante na matéria foi presença absolutamente constante durante toda a minha existência, e Teresinha Pinto Leite, que, apesar de ter nos deixado durante a realização deste trabalho, consiste em uma das maiores razões para que seguisse e concluísse.

A todos os amigos, de longa data e mais recentes, por todo o apoio em qualquer que fosse o momento: da então "maior adversidade" ao êxito, que igualmente repele os que não são verdadeiros amigos fraternais.

Ao Doutor Luiz Sergio Fernandes de Souza e ao Doutor Sérgio Coimbra Schmidt, não apenas por sua influência positiva com a maturidade decorrente do trabalho, e pela fidúcia a mim conferida. Gratidão, ainda, por momentos comuns tão agradáveis de amizade e de confiança. De igual maneira, dedico a todos meus colegas, sem exceção, referido agradecimento - por todo o convívio diário, dotado de tamanha amizade e companheirismo, tornando, ainda hoje, tantos dias aparentemente comuns em parte notável de minha vida.

Agradeço a todos os mestres de minha vida, pelas lições tão intensamente caras, e aos doutrinadores e magistrados citados. Ressalte-se o Professor Marco Fábio Morsello que, além de permitir a elaboração do presente trabalho, entre outras empreitadas passadas e futuras, ao assumir minha orientação, tanto me auxiliou nessa caminhada, bem como pelas memoráveis aulas de Direito. Muito obrigado, por todos os ensinamentos e pela amizade, que tanto prezo.

Faço menção, outrossim, à Priscilla, que não bastasse ter me ajudado tanto na formatação e revisão desse trabalho, revela-se uma grande amiga, minha e de toda a minha família. 



\section{RESUMO}

PINTO, Felipe James Arruda. Conflitos de vizinhança no Direito Civil contemporâneo. 2018. 188 f. (Mestrado) - Faculdade de Direito, Univerisdade de Sâo Paulo, São Paulo, 2018.

Importante instituto do Direito das Coisas é a propriedade, cuja definição e interpretação foi extremamente mutável no decorrer dos séculos. Assim como sempre variou sua própria natureza, também sua limitação foi discutida e discutível, sobretudo no que tange à vizinhança e ao Condomínio Edilício. Momento crucial dessa evolução se deu em Roma, passando de uma natureza quase absolutista a outros institutos e variantes proprietárias. Roma, pois, gera desdobramentos diretos na Europa Continental, é dizer, em Portugal, e, por consequência, no Brasil, que reconhece, de maneira perene, significativa relevância ao sobredito instituto político, social e jurídico. Necessária, destarte, a distinção entre Direito De Propriedade e Direito $\grave{A}$ Propriedade, a fim de compreender a dicotomia entre o direito adquirido, verdadeiro instituto consolidado, e as prerrogativas sócio-políticas a ele atreladas, com especial enfoque à dignidade da pessoa humana e à busca pela garantia de um patrimônio mínimo digno. O abuso do direito, em seu sentido lato, assim como em seu sentido estrito, é dizer, em relação ao direito de propriedade e sobre sua disposição na Constituição Federal e nas leis, denota-se imprescindível, porquanto dele se revelam os conflitos dos direitos individuais, evidentes no direito de vizinhança e nos condomínios.

A excessiva interface ocasiona distorções, abusos, bem como a necessidade de resolução desses mesmos conflitos, que não são gerados por atos ilícitos. Diga-se, outrossim, que a evolução de entendimentos sociais e doutrinários foi admitida, aos poucos, no âmbito das normas positivadas no ordenamento. Inclusive no que concerne aos princípios. A Carta Magna de 1988 trouxe diretrizes que não podem ser olvidadas, ao passo que o próprio Código Civil também releva princípios comunitários e a função social da propriedade.

Há, pois, a imposição, em detrimento de uma escolha, de ver colocada a função social da propriedade em prática na ordem do dia nacional, levando-se em conta as regras de interpretação da Constituição Federal. As questões vicinais, das quais não se evadiu a doutrina, em que pese a existência de eventuais divergências, sempre reconheceram limites na propriedade. E existe, indubitavelmente, um conjunto de princípios que orientam a resolução de conflitos, sendo inclusive plasmados por ocasião de edição normativa renovada. Notável, portanto, a chance de se responsabilizar o vizinho por suas condutas, 
arrimando-se, além disso, na doutrina e no ordenamento, porquanto inevitável a convivência vicinal. Evidencia tal interpretação, outrossim, a jurisprudência. Conquanto perceptível a dissonância na hermenêutica, resguarda-se o vizinho prejudicado, e opõe-se, com reservas, à interpretação que veda, peremptoriamente, a expulsão do condômino antissocial, sob determinados aspectos: a interpretação civil a partir da Carta Magna; a relativização da hipótese extrema de acordo com critérios que embasem o impedimento condominial; a proteção ao bem de família, entre outros aspectos descritos no presente trabalho. Cumpre prosperar a interpretação de limitação da propriedade, sob a égide da função social da propriedade e da tolerabilidade. O condômino deve se sujeitar à responsabilização, a qual deve ser efetiva, se entendida a conduta como intolerável.

Palavras-chave: Direito de propriedade. Conflitos vicinais e direito de vizinhança. Abuso do direito. Responsabilização do vizinho/condômino antissocial. 


\begin{abstract}
PINTO, Felipe James Arruda. Neighbourhood conflicts in contemporary Civil Law. 2018. 188 p. (Master) - Faculty ok Law, University of São Paulo, São Paulo, 2018.

Important institute of the Property Law is the right of property itself, whose definition and interpretation has been extremely changeable over the centuries. Just as its nature has always varied, its limitation has also been discussed and arguable, especially with regard to the neighbourhood rights and the Condominium. Crucial moment of this evolution occurred in Ancient Rome, passing from an almost absolutist nature to other proprietary institutes and variants. Rome, therefore, generates direct consequences in Continental Europe Law, thus in Portugal, and consequently in Brazil, which recognizes, in a perennial way, a significant relevance to the aforementioned political, social and juridical institute. Therefore, the distinction between Right of Property and Right to Own Property is necessary, in order to understand the dichotomy between vested right, a true consolidated institute, and the socio-political prerogatives attached to it, with a particular focus on human dignity and the seek to guarantee a minimum worthy equity. The abuse of rights, in its broad sense, as well as in its strict sense, which means, in relation to the right of property and its disposition in the Brazilian Federal Constitution and in the law system, is an essential subject, since it reveals the conflicts between individual rights, evident in the neighbourhood rights and in the Condominiums. The excessive interface causes distortions, abuses, as well as the need to resolve these same conflicts, which are not generated by illegal acts. It should also be said that the evolution of social and doctrinal understandings has gradually been admitted within the framework of the norms that are assured in the legal system. Even with regard to principles. The 1988 Constitution provided guidelines that can not be forgotten, while the Civil Code itself also emphasizes community principles and the social duty of the right of property. There is, therefore, the imposition, instead of a choice, of placing the social function of the right of property in practice on the national agenda, taking into account the rules of interpretation of the Federal Constitution. The vicissitudes, of which the doctrine was not evaded, in spite of the existence of possible divergences, always recognized limits in the right of property. And there is undoubtedly a set of principles that guide the resolution of conflicts, and are even shaped by a renewed regulatory edition. It is remarkable, therefore, the chance to hold the neighbour responsability for his conduct, according to law authors and to the law itself,
\end{abstract}


since the vicissitudes of the coexistence are inevitable. Such an interpretation, moreover, is confirmed by many precedents. Although the dissonance in hermeneutics is perceptible, the prejudiced neighbour is safeguarded, what opposes, with reservations, to the interpretation that peremptorily forbids the banishment of the anti-social owner, under certain aspects: the interpretation, within the Civil Law concepts, of the Constitutuion; the relativization of the extreme hypothesis, according to criteria that support the condominial impediment; the protection of the family property, among other aspects described in this study. The interpretation of the limitation of the right of property must prosper, within the lessons regarding the social duty of property and tolerability. The Condominium owner must be liable. Obligation, in its turn, that must be effective, if the conduct is understood as intolerable.

Key words: Right of property. Neighbourhood conflicts. Abuse of rights. Liability of the neighbour/condominium owner. 


\section{SUMÁRIO}

1 INTRODUÇÃ

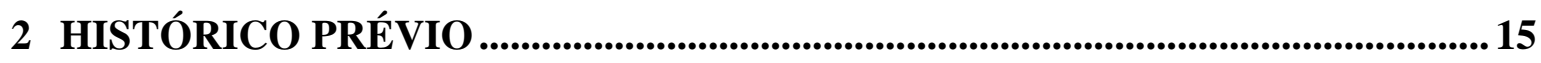

2.1 Os primórdios do Direito de Propriedade................................................................ 15

2.2 O Direito de Propriedade na Mesopotâmia ................................................................... 16

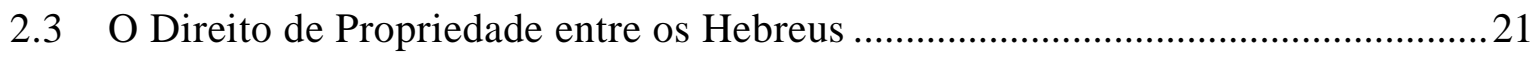

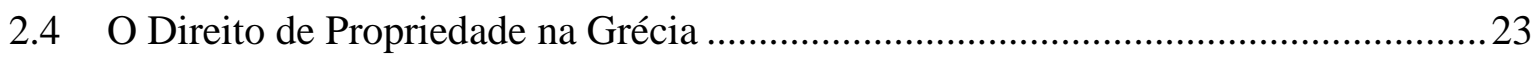

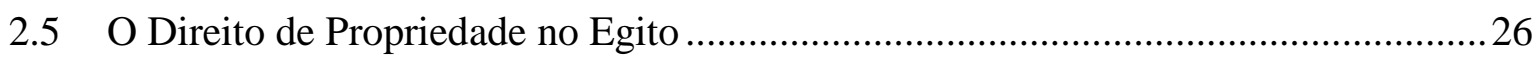

2.6 Evolução do Direito de Propriedade em Roma ........................................................... 27

2.7 O Direito de Propriedade na Idade Média e na Idade Moderna ................................... 35

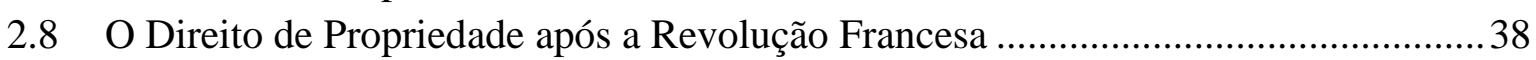

2.9 O Direito de Propriedade no Código Civil Napoleônico .............................................. 40

2.9.1 Comparação: O Direito de Propriedade nos Sistemas Inglês e Francês ...................50

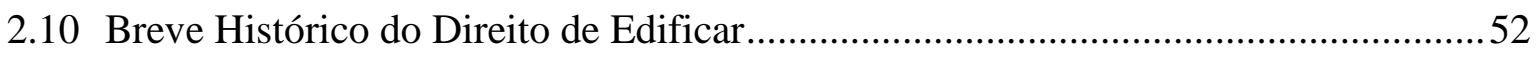

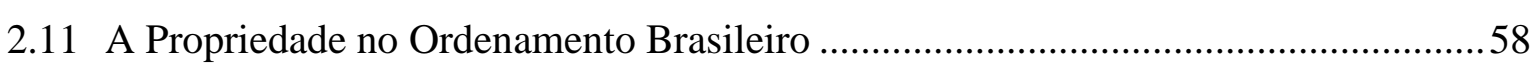

2.12 Os Direitos de Vizinhança e sua Evolução Histórica.................................................. 65

3 A DISTINÇÃo ENTRE DIREITO DE PROPRIEDAdE E DIREITO À PROPRIEDADE ................................................................................................................. 71

3.1 Distinção Clássica entre o Direito De Propriedade e o Direito À Propriedade no Brasil: Lafayette Rodrigues Pereira e os autores modernos .............. 71

3.2 Breves Comentários sobre a Distinção entre o Direito De Propriedade e o Direito À Propriedade na Doutrina Francesa ............................................................. 75

3.3 Distinção entre o Direito De Propriedade e o Direito À Propriedade no

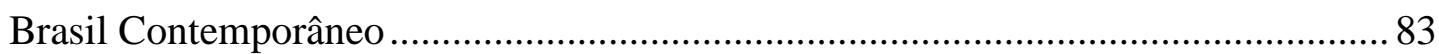

3.4 Distinção entre o Direito De Propriedade e o Direito À Propriedade no âmbito patrimonial: Luiz Edson Fachin e o Patrimônio Mínimo................................ 93

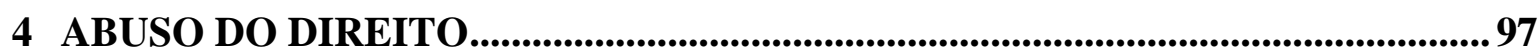

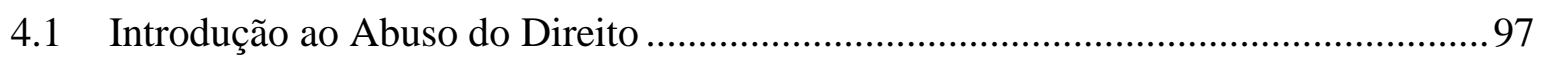

4.2 Abuso no Âmbito do Direito de Propriedade ......................................................... 100

4.3 Abuso no Âmbito da Constituição Federal e do Código Civil ................................... 104

5 GARANTIAS DO DIREITO DE PROPRIEDADE ......................................... 113

5.1 Garantias Constitucionais e Legais no Brasil........................................................... 113

5.2 Disposição das Normas que Versam Sobre os Temas no Código Civil.................... 118

5.3 Sopesamento das Normas Perante o Vizinho Antissocial ....................................... 124

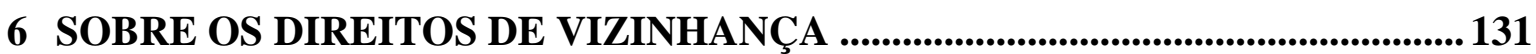

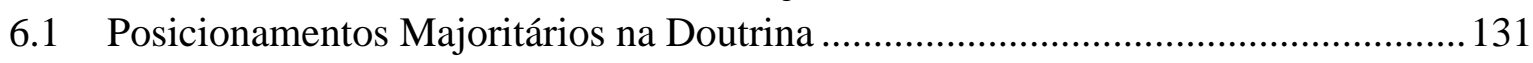

6.2 Os Limites do Direito de Vizinhança ........................................................................ 136

6.3 O Consenso Comunitário e as Modificações do Direito de Propriedade .................. 141 
7 RESPONSABILIDADE CIVIL DO VIZINHO ANTISSOCIAL .........................147

8 ANÁLISE JURISPRUDENCIAL DOS TEMAS CORRELACIONADOS ..............153

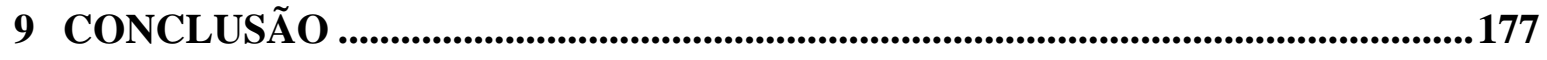

10 REFERÊNCIAS ................................................................................................. 181 


\section{INTRODUÇÃO}

Entre as matérias mais importantes do Direito Civil está o Direito das Coisas. Um relevante instituto inserido no rol dos direitos reais é a propriedade, importante direito, entendido de inúmeras maneiras ao longo do tempo. Questionou-se sempre sua limitação, sobretudo no âmbito da vizinhança e do Condomínio Edilício.

Por meio desse trabalho, aspira-se a conhecer a história da propriedade, desde o seu princípio até o presente momento, com especial destaque ao tratamento, em Roma, dos elementos supracitados, além de sua passagem para Portugal e o Brasil. Tal digressão se faz presente para entender como se desenvolveu o domínio, suas limitações e repercussões atuais.

Necessário, ainda, vislumbrar a importância da doutrina e de suas orientações divergentes, a respeito de variados ramos atinentes à propriedade, principiando pela distinção entre Direito De Propriedade e Direito $\grave{A}$ Propriedade.

Posteriormente, verifica-se o abuso do direito, não somente em sua vertente geral, cuja relevância é indiscutível, mas também com especial enfoque em relação ao direito de propriedade e sobre a disposição do tema no ordenamento pátrio, porquanto o abuso se revela sobremaneira importante quando se trata de direito de vizinhança e condomínios, em que o contato e o encontro direto dos direitos pode causar distorções, abusos, bem como impor a resolução de conflitos que não são gerados por atos ilícitos.

Pretende-se, ainda, verificar o conjunto de garantias do direito de propriedade, com especial enfoque sobre as garantias constitucionais e sobre o tratamento da temática referida nos dispositivos do atual Código Civil. No sistema jurídico brasileiro, imprescindível buscar quais são as diretrizes da propriedade e suas alterações legislativas, bem como captar a forma que ocorreu a absorção de princípios.

Em sequência, serão observados quais são os limites da propriedade e quais princípios versam sobre a resolução de conflitos. Desse modo, possível compreender se se vislumbra, no ordenamento pátrio, a hipótese de responsabilizar o vizinho por seus atos, com amparo, outrossim, legal e da Carta Magna.

Os entendimentos jurisprudenciais complementarão a abrangência do tema e sua compreensão, com o escopo de saber até que ponto é resguardado o vizinho prejudicado. Com todo esse aparato supracitado, deseja-se conhecer e dispor melhor sobre a propriedade e seu atual preceito de função social, a fim de coibir a atuação do condômino antissocial e vislumbrar se está sujeito à responsabilização. Resta, assim, iniciar o estudo da matéria. 


\section{CONCLUSÃO}

Diante dos resultados do trabalho, conclui-se, inicialmente, que a propriedade é medida constante na humanidade, ainda que em variados níveis e com diferentes enfoques. Passa por evolução de evidência em Roma, que lhe confere uma série de atributos de natureza quase absolutista. Roma deixa esse legado na Europa Continental, com destaque a Portugal, que, por sua vez, traz ao Brasil a importância elevada do referido instituto social e jurídico.

Percebe-se, outrossim, que desde sempre a propriedade sofre limitações, até mesmo por razões fáticas, sendo impossível compreender um conteúdo absoluto. Tanto as limitações pelo direito vicinal, como de outras origens, são reconhecidas, inclusive na História do Direito.

Necessário ressaltar como a evolução dos entendimentos sociais e doutrinários é absorvida de maneira crescente no âmbito das normas constantes do ordenamento. É suficientemente claro notar, ainda, como, no caso brasileiro, houve a cristalização de princípios. A Constituição Federal de 1988 trouxe diretrizes que não podem ser ignoradas, ao passo que a lei civil por excelência - o Código Civil - também releva princípios comunitários e a função social da propriedade. Tratar hodiernamente desse domínio como ilimitado não mais se comporta.

Quanto à importância da interpretação ao longo do tempo, tornando viva a ordem da Carta Magna, que deve ser estável na aplicação cotidiana do Direito:

O traço caracterizador da atividade interpretativa como fator de atualização das normas constitucionais é o fato de esta não levar a cabo qualquer mudança no texto escrito da constituição, que permanece intacto. Em outras palavras, a constituição é atualizada sem que para isso seja necessário levar a efeito qualquer alteração formal em seu texto. A via da interpretação sempre existiu; no entanto, é preciso atentar para o fato de que ela é utilizada mais em alguns países que em outros. ${ }^{184}$

Se a Constituição Federal de 1988 assegura, tão fortemente, princípios com a função social da propriedade em paralelo ao próprio direito de propriedade, afirma-se a necessidade, e não a escolha, de vê-la colocada em prática no expediente forense e político nacional, levandose em conta as regras de interpretação da Carta Magna.

Do ponto de vista jurídico, o principal traço distintivo da constituição é sua supremacia, sua posição hierárquica superior à das demais normas do sistema. As leis, atos normativos e atos jurídicos em geral não poderão existir validamente se incompatíveis com alguma norma constitucional. A constituição regula tanto o modo de produção das normas jurídicas como, também, delimita o conteúdo que possam ter. $^{185}$

${ }^{184}$ SILVA, Virgílio Afonso da. Interpretação constitucional e sincretismo metodológico. In: SILVA, Virgílio Afonso, op. cit., p. 159.

185 BARROSO, Luis Roberto; BARCELLOS, Ana Paula. O começo da história: a nova interpretação constitucional e o papel dos princípios no direito brasileiro. In: SILVA, Virgílio Afonso da (Org.). Interpretação constitucional. São Paulo: Malheiros, 2007. 
Aqui considerado, diga-se, o Código Civil e todo o ordenamento infraconstitucional acerca da propriedade.

Com base na interpretação conforme a constituição, o aplicador da norma infraconstitucional, dentre mais de uma interpretação possível, deverá buscar aquela que a compatibilize com a constituição, ainda que não seja a que mais obviamente decorra do seu texto. ${ }^{186}$

As questões vicinais foram extensamente versadas na doutrina que, apesar de eventual opinião divergente para certas orientações, sempre reconheceu os limites da propriedade. A partir de elementos comuns e gerais, com rigor teórico, foi possível solidificar um conjunto de princípios que norteiam a resolução de conflitos, sendo inclusive plasmados em ocasião de edição normativa pretérita.

Visível, pois, a realidade quanto à chance de responsabilizar o vizinho por suas condutas, arrimando-se, ademais, na norma, jamais omissa; e na doutrina, que é manifesta no sentido de observar a convivência vicinal. Evidencia a opinião aqui defendida a jurisprudência. Conquanto haja divergência na compreensão, protegido o vizinho prejudicado.

Opõe-se, apenas, à interpretação que veda absolutamente a expulsão do condômino antissocial. Se não há, de fato, questão legal a regular os termos da manutenção do proprietário em sua unidade condominial, é necessário que haja meios de prever tal sanção. Esse entendimento não afasta a demanda por um cuidado específico, oriundo de discussão social e política, aliada à elaboração legislativa em espécie.

São dois os aspectos que fundamentam a possibilidade de expulsão: a interpretação civil a partir da Constituição Federal; e a relativização da hipótese extrema de acordo com critérios que embasem o impedimento condominial.

No que tange à omissão quanto à referida figura, excetuando a jurisprudência do Rio de Janeiro, deve-se compreender que a Carta Magna trouxe um novo conjunto de diretrizes aplicáveis ao Direito Civil, de modo que se encontra difícil ignorar o visível processo que modificou o panorama da propriedade. Quanto à parcimônia, fundamental para tanto, entende-se que importa a existência de limites para a expulsão. Não basta o pedido ou mesmo a gravidade da conduta, mas sua contínua reiteração após um número elevado de atos repressores do uso anormal da propriedade.

Todas as fronteiras correntes devem ser aplicadas, havendo a proteção ao bem de família e o afastamento da expulsão em casos extremos: sem a possibilidade de mudança ou meios para que ela ocorra, os excessos da expulsão implicariam justamente o

\footnotetext{
${ }^{186}$ BARROSO, Luis Roberto; BARCELLOS, Ana Paula, op. cit.
} 
desrespeito às normas constitucionais e legais que garantem a função social da propriedade e o direito à moradia.

Coaduna-se, pois, o presente trabalho à vertente do Professor Marco Fábio Morsello, amparado, por sua vez, na lição de Antonio Junqueira de Azevedo:

O jurista Antonio Junqueira De Azevedo (...) preceitua que há uma posição
intermediária que não prega o desaparecimento do Direito Civil, muito embora
reconheça a superioridade hierárquica da Constituição, de modo que impor-se à
denominada interpretação da lei, conforme a Constituição, seguindo-se o escólio
de Konrad Hesse (...).
Referida corrente é corroborada, outrossim, por Larenz, que se escuda no
denominado personalismo ético, que é ínsito ao Direito Civil, que 'civilizou' a
Constituição. (...) Deveras, depreende-se que a Constituição, atualmente
desempenha função iluminante que não elide a interpretação conforme seus
preceitos, como elucida o Jurista Antonio Junqueira de Azevedo, (...). ${ }^{187}$

Conclui-se, destarte, que prospera a interpretação de limitação da propriedade, no atual panorama civil constitucional. Os conceitos de função social da propriedade e tolerabilidade devem prevalecer, a fim de coibir o condômino antissocial. Esse condômino se sujeita à responsabilização, a qual deve ser efetiva, se entendida a conduta como intolerável. Resta, pois, findar o exame da matéria com opção decidida e formada.

${ }^{187}$ MORSELLO, Marco Fábio, op. cit., p. 96. 



\section{REFERÊNCIAS}

ALEXY, Robert. Teoria dos direitos fundamentais. Tradução Virgílio Afonso da Silva. São Paulo: Malheiros, 2015.

ALVES, José Carlos Moreira. Direito romano. 14. ed. Rio de Janeiro: Forense, 2007.

ALVES, Vilson Rodrigues. Uso nocivo da propriedade. São Paulo: Revista dos Tribunais, 1992.

AMARAL, Francisco. Direito civil: introdução. 7. ed. Rio de Janeiro: Renovar, 2008.

ASCENSÃO, José de Oliveira. O direito: introdução e teoria geral. 6. ed. Coimbra: Almedina, 1991.

AZEVEDO, Álvaro Villaça de (Coord.). Código civil comentado. São Paulo: Atlas, 2003.

BARBOZA, Heloisa Helena, MORAES; Maria Celina Bodin de; TEPEDINO, Gustavo. Código civil interpretado. Rio de Janeiro: Renovar, 2011. 3 v.

BARROSO, Luis Roberto; BARCELLOS, Ana Paula. O começo da história: a nova interpretação constitucional e o papel dos princípios no direito brasileiro. In: SILVA, Virgílio Afonso da (Org.). Interpretação constitucional. São Paulo: Malheiros, 2007.

BLACKSTONE, William, Commentaries on the law of England, Lewis: Philadelphia, 1900.

BONFANTE, Pietro, Criterio fondamentale dei rapporti di vicinanza. Rivista di Diritto Civile, 1911.

BOULOS, Daniel M. Abuso do direito no novo Código Civil. São Paulo: Método, 2006.

BRASIL. Tribunal de Justiça de Minas Gerais. Agravo de Instrumento $n^{\circ}$ 1.0024.15.064374-0/001 13 ${ }^{\text {a }}$ Câmara Cível. Relator: Des.(a) Luiz Carlos Gomes da Mata. Julgameto: 24/08/2017. Disponível em: <http://www5.tjmg.jus.br/jurisprudencia/pesquisa PalavrasEspelhoAcordao.do? \&numeroRegistro $=9 \&$ totalLinhas $=148 \&$ paginaNumero $=9 \&$ li nhasPorPagina $=1 \&$ palavras $=\% 2522$ propriedade $\% 2522 \% 2522$ dignidade da pessoa hum ana $\% 2522 \&$ pesquisarPor=ementa\&pesquisaTesauro=true \&orderByData $=1 \&$ pesquisaPala vras=Pesquisar\&.> Acesso em 8 dez. 2017.

Tribunal de Justiça de Minas Gerais. Apelação Cível no 1.0000.17.044373-3/001 $6^{\mathrm{a}}$ Câmara Cível. Relatora: Desa. Sandra Fonseca. Julgamento: 05/09/2017. Disponível em: <http://www5.tjmg.jus.br/jurisprudencia/pesquisaPalavrasEspelhoAcordao.do?\&numeroRe gistro $=3 \&$ totalLinhas $=148 \&$ paginaNumero $=3 \&$ linhasPorPagina $=1 \&$ palavras $=\% 2522$ propr iedade $\% 2522 \% 2522$ dignidade da pessoa humana $\% 2522 \&$ pesquisarPor=ementa\&pesquisa Tesauro=true \&orderByData=1\&pesquisaPalavras=Pesquisar $\&$. Acesso em: 8 dez. 2017.

. Tribunal de Justiça de Pernambuco. Apelação nº 276741-5, 0003119-

42.2006.8.17.1090 3 $3^{\text {a }}$ Câmara de Direito Público. Relator Antenor Cardoso Soares Junior. Julgamento: 26/09/2017. Disponível em: <http://www.tjpe.jus.br/consultajurisprudencia web/xhtml/consulta/escolhaResultado.xhtml\#DOC2)>. Acesso em: 8 dez. 2017. 
Tribunal de Justiça de Pernambuco. Apelação n 433752-8, 0002237-

68.2014.8.17.0001 4 Câmara de Direito Público. Relator Rafael Machado da Cunha Cavalcanti. Julgamento: 01/09/2017. Disponível em: http://www.tjpe.jus.br/consultajuris prudenciaweb/xhtml/consulta/escolhaResultado.xhtml\#DOC2>. Acesso em 8 dez. 2017.

. Tribunal de Justiça de Pernambuco. Apelação no 442374-3, 005756058.2014.8.17.0001 6 Câmara Cível. Relator Eduardo Augusto Paura Peres. Julgamento: 20/06/2017. Disponível em: http://www.tjpe.jus.br/consultajurisprudenciaweb/xhtml/ consulta/escolhaResultado.xhtml\#DOC2>. Acesso em 8 dez. 2017.

Tribunal de Justiça de Pernambuco. Apelação n 463102-7, 002452022.2013.8.17.0001 4 Câmara de Direito Público. Relator Rafael Machado da Cunha Cavalcanti. Julgamento 19/05/2017. Disponível em: <http://www.tjpe.jus.br/consultajuris prudenciaweb/xhtml/consulta/escolhaResultado.xhtml\#DOC2>. Acesso em: 8 dez. 2017.

Tribunal de Justiça de Pernambuco. Apelação no 465812-6, 0072233-

61.2011.8.17.0001 1 ${ }^{\mathrm{a}}$ Câmara de Direito Público. Relator Fernando Cerqueira. Julgamento: 11/04/2017. Disponível em: <http://www.tjpe.jus.br/consultajurisprudenciaweb/xhtml/ consulta/escolhaResultado.xhtml\#DOC2>. Acesso em: 8 dez. 2017.

. Tribunal de Justiça de São Paulo. Apelação / Reexame Necessário no 1021441 79.2015.8.26.0071 1 $1^{a}$ Câmara Reservada ao Meio Ambiente; Foro de Bauru - $1^{\text {a }}$ Vara da Fazenda Pública. Relator: Oswaldo Luiz Palu. Julgamento: 26/10/2017. Disponível em: <https://esaj.tjsp.jus.br/cjsg/resultadoCompleta.do>. Acesso em: 8 dez. 2017.

Tribunal de Justiça de São Paulo. Apelação no 0029636-68.2011.8.26.0602 12 Câmara de Direito Privado; Foro de Sorocaba - $3^{\mathrm{a}}$. Vara Cível. Relator: Jacob Valente. Julgamento: 06/11/2014. Disponível em: <https://esaj.tjsp.jus.br/cjsg/resultadoCompleta. do>. Acesso em: 8 dez. 2017.

Tribunal de Justiça de São Paulo. Apelação no 0048673-67.2013.8.26.0002 $7^{\mathrm{a}}$ Câmara de Direito Privado; Foro Regional II - Santo Amaro - 4ª Vara da Família e Sucessões. Relator: Rômolo Russo. Julgamento: 18/04/2016. Disponível em: <https://esaj. tjsp.jus.br/cjsg/resultadoCompleta.do>. Acesso em: 8 dez. 2017.

Tribunal de Justiça do Distrito Federal. Apelação n ${ }^{\circ}$ 2007.06.1.016453-3 2 $2^{\mathrm{a}}$ Turma Recursal dos Juizados Especiais Cíveis e Criminais. Relator: Juiz Rômulo de Araújo Mendes. Julgamento: 27 de janeiro de 2009. Disponível em: <http://tjdf19.tjdft.jus.br/cgibin/tjcgi1?pq1=uso+anormal+da+propriedade\&ORIGEM=INTER\&NXTPGM=jrhtm02\&1 =20>. Acesso em: 8 dez. 2017.

Tribunal de Justiça do Distrito Federal. Apelação n ${ }^{\circ}$ 2008.08.1.000964-9 $2^{\mathrm{a}}$ Turma Recursal dos Juizados Especiais Cíveis e Criminais. Relator: Juiz Alfeu Machado. Julgamento: 21 de novembro de 2008. Disponível em: <http://tjdf19.tjdft.jus.br/cgibin/tjcgi1?pq1=uso+anormal+da+propriedade\&ORIGEM=INTER\&NXTPGM=jrhtm02\&l $=20$ >. Acesso em: 8 dez. 2017.

Tribunal de Justiça do Distrito Federal. Apelação n 20100110489329APC. Relator: Desembargador Lecir Manoel da Luz. Julgamento: 14 de dezembro de 2011. Disponível em: <http://tjdf19.tjdft.jus.br/cgi-bin/tjcgi1?ORIGEM=INTER\&pq1= condomino+antissocial\&l=20\&NXTPGM=jrhtm02>. Acesso em: 8 dez. 2017. 
Tribunal de Justiça do Estado de Minas Gerais. Apelação n ${ }^{\circ}$ 1.0515.07.0251894/001, 0251894-60.2007.8.13.0515 (1). Relator: Desembargador Fernando Caldeira Brant. Julgamento: 17/08/2011. Disponível em: <http://www.tjmg.jus.br/jurisprudencia/pesquisa PalavrasEspelhoAcordao.do? numeroRegistro $=1 \&$ totalLinhas $=1 \&$ palavras $=$ uso + anormal $+\mathrm{d}$ a+propriedade \&pesquisarPor=ementa\&pesquisaTesauro=true\&orderByData=1\&codigoOr gaoJulgador $=\&$ codigoCompostoRelator $=\&$ dataPublicacaoInicial $=\&$ dataPublicacaoFinal $=$ $\&$ dataJulgamentoInicial $=\&$ dataJulgamentoFinal $=\&$ siglaLegislativa $=\&$ referenciaLegislativ $\mathrm{a}=\mathrm{Clique}+$ na+lupa+para+pesquisar+as+refer\%EAncias+cadastradas...\&numeroRefLegislat iva $=\&$ anoRefLegislativa $=\&$ legislacao $=\&$ norma $=\&$ descNorma $=\&$ complemento_ $1=\&$ listaP esquisa $=\&$ descricaoTextosLegais $=\&$ observacoes $=\&$ linhasPorPagina $=10 \&$ pesquisaPalavra s=Pesquisar>. Acesso em: 8 dez. 2017.

Tribunal de Justiça do Estado de Minas Gerais. Apelação n 1.0145.04.1365571/001, 1365571-02.2004.8.13.0145 (1). Relator: Desembargador Elpídio Donizetti. Julgamento: 18/11/2011. Disponível em: <http://www.tjmg.jus.br/jurisprudencia/pesquisa PalavrasEspelhoAcordao.do? numeroRegistro $=1 \&$ totalLinhas $=1 \&$ palavras $=$ uso + anormal $+d$ a+propriedade \&pesquisarPor $=$ ementa\&pesquisaTesauro $=$ true \&orderByData $=1 \&$ codigoOr gaoJulgador $=\&$ codigoCompostoRelator $=\&$ dataPublicacaoInicial $=\&$ dataPublicacaoFinal $=$ $\&$ dataJulgamentoInicial $=\&$ dataJulgamentoFinal $=\&$ siglaLegislativa $=\&$ referenciaLegislativ $a=$ Clique+na+lupa+para+pesquisar+as+refer\%EAncias+cadastradas...\&numeroRefLegislat iva $=\&$ anoRefLegislativa $=\&$ legislacao $=\&$ norma $=\&$ descNorma $=\&$ complemento_ $1=\&$ listaP esquisa $=\&$ descricaoTextosLegais $=\&$ observacoes $=\&$ linhasPorPagina $=10 \&$ pesquisaPalavra s=Pesquisar>. Acesso em: 8 dez. 2017.

Tribunal de Justiça do Estado de Minas Gerais. Apelação n ${ }^{\circ}$.0024.05.8111964/001, 8111964-74.2005.8.13.0024 (1). Relatora: Desembargadora Evangelina Castilho Duarte. Julgamento: 10/01/2008. Disponível em: <http://www.tjmg.jus.br/jurisprudencia/ pesquisaPalavrasEspelhoAcordao.do?numeroRegistro $=1 \&$ totalLinhas $=1 \&$ palavras $=$ cond $\%$ F4mino+anti+social\&pesquisarPor $=$ ementa\& pesquisaTesauro $=$ true \&orderByData $=1 \&$ codi goOrgaoJulgador $=\&$ codigoCompostoRelator $=\&$ dataPublicacaoInicial=\&dataPublicacaoFi nal=\&dataJulgamentoInicial $=\&$ dataJulgamentoFinal $=\&$ siglaLegislativa $=\&$ referenciaLegisl ativa $=$ Clique+na+lupa + para+pesquisar+as+refer\%EAncias+cadastradas...\&numeroRefLeg islativa $=\&$ anoRefLegislativa $=\&$ legislacao $=\&$ norma $=\&$ descNorma $=\&$ complemento_ $1=\&$ li staPesquisa $=\&$ descricaoTextosLegais $=\&$ observacoes $=\&$ linhasPorPagina $=10 \&$ pesquisaPal avras=Pesquisar $>$. Acesso em: 8 dez. 2017.

Tribunal de Justiça do Estado de Pernambuco. Apelação n ${ }^{\circ}$ 1870026756, 5537-2; Relator: Desembargador Waldemir Lins. Julgamento: 05/04/ 1995. Disponível em: <http:// www.tjpe.jus.br/jurisprudencia/resposta_processo.asp?CodProc $=5547 \&$ Numero $=5537200$ $\&$ Destaque $=$ uso $\% 20$ anormal $\% 20 \mathrm{da} \% 20$ propriedade $\&$ Registros $=1 \&$ Registro $=1 \&$ Lista $=$ Pes qJurispFULLTEXT\%20'uso $\% 20<$ and $>\% 20$ anormal $\% 20<$ and $>\% 20 \mathrm{da} \% 20<$ and $>\% 20$ propr iedade','\%20',-1,-1,'\%20',-1,'\%20',",'\%20',">. Acesso em: 8 dez. 2017.

Tribunal de Justiça do Estado de São Paulo. Agravo de Instrumento n ${ }^{\circ} 0108401$ 79.2012.8.26.0000. Relator: Desembargador Marcos Ramos. Julgamento: 18/07/2012. Disponível em: <http://esaj.tj.sp.gov.br/cjsg/resultadoCompleta.do>. Acesso em: 8 dez. 2017.

. Tribunal de Justiça do Estado de São Paulo. Apelação n ${ }^{\circ} 0116123$ -

39.2009.8.26.0011. Relator: Desembargador Pereira Calças. Julgamento: 08/08/2012. Disponível em: <http://esaj.tj.sp.gov.br/cjsg/resultadoCompleta.do>. Acesso em: 8 dez. 2017. 
Tribunal de Justiça do Estado de São Paulo. Apelação n $0044746-$

67.2010.8.26.0562. Relator: Desembargador Marcondes D’Angelo. Julgamento: 18/07/2012. Disponível em: <http://esaj.tj.sp.gov.br/cjsg/resultadoCompleta.do>. Acesso em: 8 dez. 2017.

. Tribunal de Justiça do Estado de São Paulo. Apelação n 0230616-24.2007.8.26.0100. Relator: Desembargador Moreira Viegas. Julgamento: 01/08/2012. Disponível em: <http://esaj.tj.sp.gov.br/cjsg/resultadoCompleta.do>. Acesso em: 8 dez. 2017.

. Tribunal de Justiça do Estado do Rio de Janeiro. Apelação n $0000371-$ 09.2006.8.19.0079, 2008.001.27564. Relatora: Desembargadora Myriam Medeiros da Fonseca Costa. Julgamento: 30/09/2008. Disponível em:

$<$ http://www.tjrj.jus.br/institucional/dir_gerais/dgcon/pdf/jurisprudencia/selecao/consumid or/animal-apartamento.pdf >. Acesso em: 8 dez. 2017.

. Tribunal de Justiça do Rio de Janeiro. Apelação n 0168659-23.2007.8.19.0001

Segunda Câmara Cível. Des. Jessé Torres Pereira Júnior. Julgamento: 11/02/2009. Disponível em: <http://www4.tjrj.jus.br/EJURIS/ImpressaoConsJuris.aspx?CodDoc $=856166 \&$ EmenPorAss $=$ true $\&$ PageSeq=1>. Acesso em: 8 dez .2017.

. Tribunal de Justiça do Rio de Janeiro. Agravo de Instrumento no $0060354-$ 06.2011.8.19.0000 Décima Sexta Câmara Cível. Relator: Des(a). Marco Aurélio Bezerra de Melo. - Julgamento: 24/01/2012. Agravo de Instrumento no 0009983-34.1994.8. 19.0000. Relator: Des. Humberto de Mendonça Manes. Julgamento: 14/02/1995. Disponível em: <http://www4.tjrj.jus.br/EJURIS/ImpressaoConsJuris.aspx ?CodDoc=1 452074\&EmenPorAss=true\&PageSeq=0> . Acesso em: 8 dez. 2017.

. Tribunal de Justiça do Rio de Janeiro. Apelação Cível nº 2005.001.09232. Relator: Des. Maria Augusta Vaz. Julgamento: 24/05/2005 e Agravo de Instrumento ${ }^{\circ}$ 2003.002.04915. Relator Des. Joaquim Alves de Brito. Julgamento: 05/08/2004. Disponível em: <http://www4.tjrj.jus.br/ejud/ConsultaProcesso.aspx?N=2006.001.61775>. Acesso em 8 dez. 2017.

. Tribunal de Justiça do Rio de Janeiro. Apelação Cível nº 002446597.2002.8.19.0002 Quarta Câmara Cível. Relator: Des(a). Reinaldo Pinto Alberto Filho. Julgamento: 09/01/2007. Disponível em: <http://www4.tjrj.jus.br/ejud/ConsultaProcesso .aspx?N=2006.001.61775>. Acesso em: 8 dez. 2017.

. Tribunal de Justiça do Rio de Janeiro. Apelação n ${ }^{\circ}$ 0026235-24.2008.8.19.0000, 2008.002.1823. Relator: Desembargador Luiz Fernando Ribeiro de Carvalho. Julgamento: 20/07/2008. Disponível em: <http://www.tjrj.jus.br/institucional/dir_gerais/dgcon/pdf/ jurisprudencia/selecao/consumidor/animal-apartamento.pdf>. Acesso em: 8 dez. 2017.

Tribunal de Justiça do Rio de Janeiro. Apelação n ${ }^{\circ}$ 0042255-53.2009.8.19.0001. Relatora: Desembargadora Ana Maria Oliveira. Julgamento: 28/09/2010. Disponível em: <http://www.tjrj.jus.br/c/document_library/get_file?uuid=a0aba3da-5de6-47e2-a3decfc4b1ae5644\&groupId=10136>. Acesso em: 8 dez. 2017.

. Tribunal de Justiça do Rio de Janeiro. Apelação nº 0323611-52.2010.8.19.0001

Oitava Câmara Cível. Desa. Mônica Maria Costa di Piero. Julgamento: 05/04/2016.

Disponível em: <http://www4.tjrj.jus.br/EJURIS/ImpressaoConsJuris.aspx?

CodDoc $=3097322 \&$ EmenPorAss=true $\&$ PageSeq=0> . Acesso em: 8 dez. 2017. 
Tribunal de Justiça do Rio de Janeiro. Processo Administrativo no ${ }^{\circ}$ 003204657.2011.8.19.0000 Secretaria do Tribunal Pleno e Órgão Especial. Des. Luiz Felipe da Silva Haddad. Julgamento: 07/11/2011. Disponível em: <http://www4.tjrj.jus.br/EJURIS/ ImpressaoConsJuris.aspx CodDoc $=1853105 \&$ EmenPorAss $=$ true $\&$ PageSeq $=1>$. Acesso em: 8 dez. 2017.

Tribunal de Justiça do Rio Grande do Sul. Agravo de Instrumento ${ }^{\circ} 70036892115$; Relatora: Desembargadora Liege Puricelli Pires. Julgamento: 19/08/2010. Disponível em: $<$ http://www1.tjrs.jus.br/busca/?q=uso+anormal+da+propriedade \&tb=jurisnova\&partialfiel $\mathrm{ds}=$ tribunal $\% 3 \mathrm{ATribunal} \% 2520 \mathrm{de} \% 2520 \mathrm{Justi} \% 25 \mathrm{C} 3 \% 25 \mathrm{~A} 7 \mathrm{a} \% 2520 \mathrm{do} \% 2520 \mathrm{RS} . \% 28 \mathrm{Tip}$ oDecisao\%3Aac\%25C3\%25B3rd\%25C3\%25A3o\%7CTipoDecisao\%3Amonocr\%25C3\%2 5A1tica\%7CTipoDecisao\%3Anull\%29\&requiredfields=\&as_q=>. Acesso em: $8 \mathrm{dez}$. 2017.

. Tribunal de Justiça do Rio Grande do Sul. Apelação Cível no 70067757849 Vigésima Câmara Cível. Relator: Alexandre Kreutz. Julgamento: 05/07/2017. Disponível em: <em http://www.tjrs.jus.br/busca/search?q=\%22fun\%C3\%A7\%C3\%A3o+social+da+ propriedade $\% 22 \&$ proxystylesheet $=$ tjrs_index \&getfields $=* \&$ entsp $=$ a_politica-site $\& W C$ $=200 \& w c \_m c=1 \& o e=U T F-8 \& i e=U T F-8 \& u d=1 \&$ sort=date:D:S:d1\&as_qj=\%22prote\% C3\%A7\%C3\%A3o+da+propriedade $\% 22 \&$ as_epq=\&as_oq=\&as_eq=\&as_q=+\&ulang=pt$\mathrm{BR} \& \mathrm{ip}=186.220 .139 .115 \&$ access $=\mathrm{p} \&$ entqr $=3 \&$ entqrm $=0 \&$ client $=$ tjrs_index \&filter $=0 \&$ sta $\mathrm{rt}=10 \& a b a=j u r i s \&$ site=ementario\#main_res_juris $>$. Acesso em: 8 dez. 2017.

Tribunal de Justiça do Rio Grande do Sul. Apelação Cível no 70070560412 Décima Nona Câmara Cível. Relatora: Mylene Maria Michel. Julgamento: 22/06/2017Disponível em: <http://www.tjrs.jus.br/busca/search?q=\%22propriedade\%22+\%22dignidade+da+ pessoa+humana $\% 22 \&$ proxystylesheet $=$ tjrs_index \&getfields $=* \&$ entsp $=$ a_politicasite $\& w c=200 \& w c \_m c=1 \& o e=U T F-8 \& i e=U T F-8 \& u d=1 \&$ sort=date:D:S:d1\&as_qj=\&as _epq $=\& a s \_o q=\&$ as_eq $=\& a s \_q=+\& u l a n g=p t-B R \& i p=186.220 .139 .115 \&$ access $=p \& e n t q r=$ $3 \&$ entqrm $=0 \&$ client $=$ tjrs_index \&filter $=0 \&$ start $=10 \& a b a=j u r i s \&$ site $=$ ementario\#main_res_ juris>. Acesso em: 8 dez. 2017.

Tribunal de Justiça do Rio Grande do Sul. Apelação Cível no 70072184633 Décima Nona Câmara Cível. Relator: Marco Antonio Angelo> Julgamento: 14/09/2017. Disponível em: <http://www.tjrs.jus.br/busca/search?q=\%22propriedade\%22+\%22dig nidade+da+pessoa+humana $\% 22 \&$ proxystylesheet $=$ tjrs_index \&client $=$ tjrs_index \&filter $=0$ $\&$ getfields $=* \& a b a=$ juris \&entsp $=$ a_politica-site $\& w c=200 \& w c \_m c=1 \& o e=U T F-$ 8\&ie=UTF-8\&ud=1\&sort=date $\% 3 \mathrm{AD} \% 3 \mathrm{AS} \% 3 \mathrm{Ad} 1 \&$ as_qj=\&site=ementario\&as _epq=\&as_oq=\&as_eq=\&as_q=+\#main_res_juris>. Acesso em: 8 dez. 2017.

. Tribunal de Justiça do Rio Grande do Sul. Apelação Cível no 70072513062 Décima Nona Câmara Cível. Relator: Eduardo João Lima Costa. Julgamento: 13/07/2017. Disponível em: <http://www.tjrs.jus.br/busca/search?q=\%22fun\%C3\%A7\%C3\%A3o+ social+da+propriedade $\% 22 \&$ proxystylesheet $=$ tjrs_index $\&$ getfields $=* \& e n t s p=a \_$politicasite $\& w c=200 \& w c \_m c=1 \& o e=U T F-8 \& i e=U T F-8 \& u d=1 \&$ sort $=$ date:D:S:d1\&as_qj=\%22 prote $\%$ C3\%A7\%C3\%A3o+da+propriedade $\% 22 \&$ as_epq $=\& a s \_o q=\& a s \_e q=\& a s \_q=+\& u l a$ ng=pt-BR\&ip $=186.220 .139 .115 \&$ access $=p \&$ entqr $=3 \&$ entqrm $=0 \&$ client $=$ tjrs_index \&filter $=0 \&$ start $=10 \& a b a=$ juris $\&$ site $=$ ementario\#main_res_juris $>$. Acesso em 8 dez. 2017. 
Tribunal de Justiça do Rio Grande do Sul. Apelação Cível no 70073307233 Décima Nona Câmara Cível. Relator: Eduardo João Lima Costa. Julgamento: 17/08/2017. Disponível em: <http://www.tjrs.jus.br/busca/search?q=\%22propriedade\%22+\%22 dignidade+da+pessoa+humana $\% 22 \&$ proxystylesheet $=$ tjrs_index\&getfields $=* \&$ entsp $=\mathrm{a} \_$_p olitica-site \&wc $=200 \& w c \_m c=1 \& o e=U T F-8 \& i e=U T F-8 \& u d=1 \&$ sort=date:D:S:d1\&as _qj=\&as_epq=\&as_oq=\&as_eq=\&as_q=+\&ulang=pt-BR\&ip=186.220.139.115\&Access $=$ p\&entqr $=3 \&$ entqrm $=0 \&$ client $=$ tjrs_index \&filter $=0 \&$ start $=10 \& a b a=j u r i s \&$ site $=$ ementario \#main_res_juris>. Acesso em: 8 dez. 2017.

. Tribunal de Justiça do Rio Grande do Sul. Apelação Cível No 70073603326 Décima Sétima Câmara Cível. Relator: Giovanni Conti. Julgamento: 20/07/2017. Disponível em: <http://www.tjrs.jus.br/busca/search?q=\%22propriedade\%22+\%22dign idade+da+pessoa+humana $\% 22 \&$ proxystylesheet $=$ tjrs_index \&getfields $=* \&$ entsp $=$ a_politi ca-site \&wc $=200 \& w c \_m c=1 \& o e=U T F-8 \& i e=U T F-8 \& u d=1 \&$ sort=date:D:S:d1\&as_qj=\& as_epq $=\&$ as_oq $=\&$ as_eq $=\&$ as_q $=+\& u l a n g=p t-B R \& i p=186.220 .139 .115 \&$ access $=$ p \&entqr $=3 \&$ entqrm $=0 \&$ client $=$ tjrs_index \&filter $=0 \&$ start $=10 \& a b a=j u r i s \&$ site $=$ ementario\#main_res _juris>. Acesso em: 8 dez. 2017.

. Tribunal de Justiça do Rio Grande do Sul. Apelação Cível no 70064081227 Terceira Câmara Cível. Relator: Leonel Pires Ohlweiler. Julgamento: 29/06/2017. Disponível em: <http://www.tjrs.jus.br/busca/search?q=\%22propriedade\%22+\%22dignid ade+da+pessoa+humana $\% 22 \&$ proxystylesheet $=$ tjrs_index $\&$ getfields $=* \&$ entsp $=$ a__politica -site \&wc=200\&wc_mc=1\&oe=UTF-8\&ie=UTF-8\&ud=1\&sort=date:D:S:d1\&as_qj=\&as_ epq=\&as_oq=\&as_eq=\&as_q=+\&ulang=pt-BR\&ip=186.220.139.115\&access=p\&entqr= $3 \&$ entqrm $=0 \&$ client $=$ tjrs_index \&filter $=0 \&$ start=10\&aba $=$ juris $\&$ site $=$ ementario\#main_res_ juris)>. Acesso em: 8 dez. 2017.

Tribunal de Justiça do Rio Grande do Sul. Apelação nº 70036962447. Relatora Desembargadora Bernadete Coutinho Friedrich. 28 de outubro de 2010. Disponível em: $<$ http://www1.tjrs.jus.br/busca/?q=uso+anormal+da+propriedade $\&$ tb=jurisnova\&partialfiel $\mathrm{ds}=$ tribunal $\% 3$ ATribunal $\% 2520 \mathrm{de} \% 2520 \mathrm{Justi} \% 25 \mathrm{C} 3 \% 25 \mathrm{~A} 7 \mathrm{a} \% 2520 \mathrm{do} \% 2520 \mathrm{RS} . \% 28 \mathrm{Tip}$ oDecisao $\% 3 \mathrm{Aac} \% 25 \mathrm{C} 3 \% 25 \mathrm{~B} 3 \mathrm{rd} \% 25 \mathrm{C} 3 \% 25 \mathrm{~A} 3 \mathrm{o} \%$ 7CTipoDecisao $\% 3 \mathrm{Amonocr} \% 25 \mathrm{C} 3 \% 2$ 5A1tica\%7CTipoDecisao\%3Anull\%29\&requiredfields=\&as_q=>. Acesso em: $8 \mathrm{dez}$. 2017.

Tribunal de Justiça do Rio Grande do Sul. Apelação n 70040098600 . Relatora: Desembargadora Liege Puricelli Pires. Julgamento: 08/09/2011. Disponível em: $<$ http://www1.tjrs.jus.br/busca/?q=cond\%F4mino+antissocial\&tb=jurisnova\&partialfields =tribunal\%3ATribunal $\% 2520 \mathrm{de} \% 2520 \mathrm{Justi} \% 25 \mathrm{C} 3 \% 25 \mathrm{~A} 7 \mathrm{a} \% 2520 \mathrm{do} \% 2520 \mathrm{RS} . \% 28 \mathrm{Tipo}$ Decisao\%3Aac\%25C3\%25B3rd\%25C3\%25A3o\%7CTipoDecisao\%3Amonocr\%25C3\%25 A1tica\%7CTipoDecisao\%3Anull\%29\&requiredfields=\&as_q=>. Acesso em: 8 dez. 2017.

CANOTILHO, José Joaquim Gomes. Direito constitucional e teoria da Constituição. 7. ed. Coimbra: Almedina, 2003.

CARBONNIER, Jean. Droit civil introduction. 18. ed. Paris: Presses universitaires de France, 1988.

. Droit civil tome 3: les biens, monnaie, immeubles, meubles. 12. ed. Paris: Presses universitaires de France, 1988. 
DANTAS, Francisco Clementino de San Tiago. Conflito de vizinhança e sua composição. Rio de Janeiro: [s.l.], 1939.

DE LOS MOZOS, Jose Luis. El derecho de propriedad: crisis y retorno a la tradición jurídica. Madrid: Editorial Revista de Derecho Privado - Editoriales de Derecho Reunidas, 1993.

DUARTE, Nestor. Comentários à parte geral. In: PELUSO, César (Coord.). Código Civil comentado. 5. ed. Barueri: Manole, 2011.

DWORKIN, Ronald. Levando os direitos a sério. Tradução Nelson Boeira São Paulo: Martins Fontes, 2011.

FACHIN, Luiz Edson. Estatuto jurídico do patrimônio mínimo. Rio de Janeiro: Renovar, 2001.

GAMBARO, Antonio. Jus aedificandi e nozione civilistica della proprietà. Milão: Giuffrè, 1975.

GAUDEMET, Jean. Les institutions de l'antiquite. Paris: Sirey, 1967.

GIDDENS, Anthony. Mundo em descontrole. Tradução Maria Luiza X. de A. Borges. Rio de Janeiro: Record, 2007.

GILISSEN, John. Introdução histórica ao direito. Tradução António M. Hespanha e L. M. Macaísta Malheiros. 5. ed. Lisboa: Fundação Calouste Gulbenkian, 2008.

HESSE, Konrad. A força normativa da constituição. Porto Alegre: Sergio Antonio Fabris Editor, 1991.

LIBERATORE, Pasquale Maria. Osservazioni sul titolo secondo de delvincourt - corso di diritto civile. Nápoles: [s.1.], 1828. Tradução para o italiano.

LOPES, José Reinaldo de Lima. O direito na história: lições introdutórias. 3. ed. São Paulo: Atlas, 2008.

LOUREIRO, Francisco Eduardo. A propriedade como relação jurídica complexa. Rio de Janeiro: Renovar, 2003. 2011. In: PELUSO, César (Coord.). Código civil comentado. 5. ed. Barueri: Manole,

MALUF, Carlos Alberto Dabus. Limitações ao direito de propriedade. 2. ed. São Paulo: Revista dos Tribunais, 2005.

; MONTEIRO, Washington de Barros. Curso de direito civil. 40. ed. São Paulo: Saraiva, 2010. 3 v.

MAXIMILIANO, Carlos. Hermenêutica e aplicação do direito. 18. ed. Rio de Janeiro: Forense, 2000. 
MORSELLO, Marco Fábio. Direito civil constitucional e o direito de propriedade no Brasil e no direito comparado. Revista da Pós-Graduação da Faculdade de Direito da Universidade de São Paulo, Porto Alegre, v. 2, 2000.

NERY JUNIOR, Nelson; NERY, Rosa Maria de Andrade. Código civil comentado. 6. ed. São Paulo: Revista dos Tribunais, 2008. ; __ Constituição federal comentada e legislação constitucional. 2. ed. São Paulo: Revista dos Tribunais, 2009.

PELUSO, César (Coord.). Código civil comentado. 5. ed. Barueri: Manole, 2011.

PENTEADO, Luciano de Camargo. Direito das coisas. 3. ed. rev. atual. ampl. São Paulo: Revista dos Tribunais, 2014.

PEREIRA, Lafayette Rodrigues. Direito das coisas. 5. ed. Rio de Janeiro: Freitas Bastos, 1943. $1 \mathrm{v}$.

RADBRUCH, Gustav. Filosofia do direito. Tradução L. Cabral de Moncada. Coimbra: Arménio Amado, 1997.

RÁO, Vicente. O direito e a vida dos direitos. 6. ed. São Paulo: Revista dos Tribunais, 2005. Obra atualizada por Ovídio Rocha Barros Sandoval.

RODOTÀ, Stefano. Il terribile diritto: studi sulla proprietà privata. 2. ed. Bolonha: Società editrice il Mulino, 1990.

SÁ, Francisco Augusto Cunha de. Abuso do direito. Lisboa: Centro de Estudos Fiscais da Direcção-Geral das Contribuições e Impostos, Ministério das Finanças, 1973.

SILVA, Nuno Espinosa Gomes da. História do direito português: fontes do direito. Lisboa: Associação Acadêmica da Faculdade de Direito de Lisboa, 1980.

SILVA, Virgílio Afonso da (Org.). Interpretação constitucional. São Paulo: Malheiros, 2007.

TEIXEIRA DE FREITAS, Augusto. Consolidação das leis civis. Brasília: Senado Federal, 2003. $1 \mathrm{v}$.

TEPEDINO, Gustavo. Temas de direito civil. 4. ed. Rio de Janeiro: Renovar, 2008.

TERRÉ, François. L'évolution du droit de propriété depuis le Code Civil. Droits Revue Française de Théorie Juridique. Paris, 1985.

VENOSA, Sílvio de Salvo. Direito das coisas. Posse. Direitos Reais. Propriedade. Artigos 1.196 a 1.368. In: AZEVEDO, Álvaro Villaça de (Coord.). Código civil comentado. São Paulo: Atlas, 2003. 12 v.

VIEHWEG, Theodor. Tópica e jurisprudência. Tradução Tércio Sampaio Ferraz Jr. Brasília: Imprensa Nacional, 1979. 